\title{
Elementos do jogo da linguagem: um estudo sobre pistas e enquadres em uma entrevista da Rádio Macau
}

\author{
Mariana Kuhlmann (FFLCH - USP) ${ }^{1}$
}

Resumo: Ao assumir o uso da linguagem como um jogo (WITTGENSTEIN, 1952 apud MARCONDES, 2006, p. 221) em que os sujeitos constroem as suas identidades, desenvolveremos um estudo dedicado a analisar as pistas de contextualização mobilizadas pelos falantes durante o ato comunicativo. Empreenderemos, então, uma incursão na transcrição de uma entrevista da Rádio Macau para verificar como entrevistador e entrevistado conduzem definição e sinalização dos enquadres situacionais e o que as pistas indicam sobre a interação.

Palavras-chave: linguagem; pistas; enquadres; interação verbal.

\section{Introdução}

Quando nos dedicamos a observar a linguagem nas sociedades não letradas, temos a oportunidade de apreender como ela comporta aspectos cruciais que sustentam as relações comunicativas:

A língua é desenvolvida em associação íntima com a experiência da comunidade e é aprendida pelo indivíduo no contato face-a-face com os outros membros. O que continua a ser de relevância social é armazenado na memória, enquanto o resto é normalmente esquecido: e a linguagem - sobretudo, o vocabulário - é o meio efetivo desse processo crucial de digestão e eliminação social que pode ser visto como análogo à organização homeostática do corpo humano por meio da qual ele tenta manter sua condição de vida presente. (GOODY e WATT, 2006, p. 17).

O uso da linguagem, por eliminar convenções e valores que não são relevantes e abrigar e transmitir as que são relevantes para uma comunidade, faz com que estudá-lo seja uma tarefa que perpassa pela questão da identidade

1 Graduanda do curso de Letras da Faculdade de Filosofia, Letras e Ciências Humanas da Universidade de São Paulo e pesquisadora de Iniciação Científica do PIBIC/CNPq. E-mail: mariana.kuhlmann@usp.br. As questões apresentadas nesse artigo resultam das reflexões propostas pelo Prof. Dr. Roberval Teixeira e Silva na disciplina Linguagem, Cultura e Interação: Construção de Identidades em Lingua Portuguesa no Contexto de Macau, ministrada no Programa de PósGraduação em Filologia e Língua Portuguesa da Faculdade de Filosofia, Letras e Ciências Humanas da Universidade de São Paulo. 
que é assumida pelo todo. Isso porque as relações estabelecidas por meio da linguagem - escrita ou oral - estão impregnadas por tais convenções e valores.

Assim sendo, o sujeito comunicativamente competente em uma língua diferencia as regras socioculturais que caracterizam os enquadres situacionais e mobiliza as pistas de contextualização para indicar tais enquadres.

As considerações iniciais apresentadas sedimentam o cerne do estudo proposto: por meio dos conceitos de pistas de contextualização e enquadre, pretendemos compreender a interação verbal enquanto um jogo social em que se pode depreender o papel que cada sujeito assume; para isso, usaremos a transcrição de uma entrevista da Rádio Macau².

\section{Interação verbal: o jogo da linguagem}

Abordar a interação verbal a partir de uma perspectiva pragmática nos leva a assumir que o contexto determina a interpretação de uma mensagem. Isso porque, o uso da linguagem está sujeito a fatores como convenções culturais, tempo, intenções comunicativas, posição social dos falantes, enfim, a "condições que governam a utilização da linguagem, a prática linguística" (FIORIN, 2008, p. 166).

Wittgenstein (1952 apud MARCONDES, 2006, p. 221) apresenta uma visão pragmática da linguagem ao postular que o significado de uma palavra adotado em uma situação é definido pelo seu uso em um determinado no contexto:

Segundo Wittgenstein, o significado não deve ser entendido como algo de fixo e determinado, como uma propriedade inerente à palavra, mas sim como a função que as expressões linguísticas exercem em um contexto específico e com objetivos específicos. O significado pode, por conseguinte, variar dependendo do contexto em que a palavra é utilizada e do propósito deste uso (MARCONDES, 2006, p. 221).

Wittgenstein (1952 apud MARCONDES, 2006, p. 222) emprega a expressão jogo de linguagem para se referir aos diferentes contextos das interações:

Os jogos são jogados de acordo com regras que podem ser mais ou menos explícitas, mais ou menos formais. Do mesmo modo, os jogos de linguagem possuem regras que definem o que é ou não válido, segundo as quais os objetivos podem ser alcançados.

${ }^{2}$ A entrevista selecionada para estudo pertence ao corpus de entrevistas transcritas pelo Grupo de Pesquisa Mudança Gramatical do Português - CNPq/USP. 
Cabe aos sujeitos reconhecer tais regras e adequar o seu discurso para que o andamento do jogo - a interação - seja conduzido de acordo com os objetivos comunicativos e papéis assumidos no ato comunicativo.

\section{Pistas e enquadres: as peças do jogo}

Conforme a perspectiva wittgesteiniana, o jogo é entendido como a interação comunicativa; os jogadores são os sujeitos envolvidos na interação; e, por fim, as regras do jogo são as condições pragmáticas. Mas assumir essa perspectiva nos leva a contemplar uma questão: quais seriam as peças desse jogo?

São muitas. A que consideraremos nesse trabalho são as pistas e os enquadres.

É preciso compreender que socializar é uma tarefa que exige a habilidade de identificar, nas interações, as particularidades de cada evento de fala. De acordo como Hymes (1972) os eventos de fala são caracterizados por oito fatores: situação, participantes, fins/propósitos, atos conversacionais, aspectos emocionais e de formalidade/informalidade, meio, normas de interpretação e produção e gêneros discursivos.

Por essa razão, parece razoável nos posicionar em concordância com Tannen e Wallat (2002, p. 183): o jogo discursivo, por operar em diferentes níveis e ser constituído por diferentes fatores, é complexo, até mesmo em eventos de fala altamente ritualizados.

Os eventos de fala, a interação comunicativa, o jogo discursivo são termos que estão alinhados, basicamente, ao que se entende por enquadre - a perspectiva situacional. Segundo Tannen e Wallat (2002, p. 189), a noção interativa de enquadre refere-se à percepção de qual atividade está sendo encenada, de qual sentido os falantes dão ao que dizem: "Dado que esse sentido é percebido a partir da maneira como os participantes se comportam na interação, os enquadres emergem de interações verbais e não-verbais e são por elas constituídos".

Por sua vez, as pistas de contextualização viabilizam a leitura dos enquadres e determinam como deve ser o comportamento dos sujeitos e quais são as suas expectativas. Por meio delas, os interagentes sinalizam e interpretam qual é a atividade que está ocorrendo, como o conteúdo semântico deve ser entendido e como cada oração se relaciona ao que a precede ou sucede (GUMPERZ, 2002, p. 152):

Grosso modo, as pistas de contextualização são todos os traços linguísticos que contribuem para a sinalização de pressupostos contextuais. Tais pistas podem aparecer sob várias manifestações 
linguísticas, dependendo do repertório linguístico, historicamente determinado, de cada participante (GUMPERZ, 2002, p. 153).

\section{A Rádio Macau}

Apresentaremos breves considerações sobre a fonte do material usado no estudo que empreenderemos: a Rádio Macau.

A Teledifusão de Macau (TDM), empresa pública fundada em 1982, foi o órgão responsável pelos serviços de radiodifusão sonora e televisiva em Macau até 1988. O encerramento das suas atividades se deu pelo pretexto de ser introduzida uma nova dinâmica de funcionamento. No mesmo ano é criada a Teledifusão de Macau, S.A (TDM).

A Rádio Macau é a estação de rádio vinculada à TDM, tendo um canal chinês e um português. Segundo o Gabinete de Comunicação Social da Região Administrativa de Macau $^{3}$, ambos emitem um total de 336 horas semanais. A estação transmite noticiários, programas de entrevistas, de música, de assuntos gerais e disponibiliza o conteúdo transmitido na internet ${ }^{4}$.

Utilizaremos, no presente estudo, a transcrição de uma entrevista realizada em 20/03/2009 entre Miguel Senna Fernandes - entrevistado - e Gilberto Lopes - entrevistador - no programa Rádio Macau Entrevista. Trata-se de um programa sem intervalos, que dura, aproximadamente, uma hora e que discute temas referentes à realidade macaense e à atuação do entrevistado na comunidade.

\section{Estudo de caso}

Da supracitada entrevista, destacaremos quatro momentos e as pistas de contextualização que caracterizam os enquadres.

O entrevistador inaugura o jogo comunicativo da seguinte forma:

GL: advogado de profissão Miguel Senna Fernandes é presidente da Associação dos Macaenses e lider do Grupo Doci Papiaçam di Macau... membro de uma das famílias com maior histórico do território, tem contribuido para que o patuá não desapareça... boa tarde doutor MS Fernandes...

MS: muito boa tarde

\footnotetext{
${ }^{3}$ Desde 2002, o Gabinete de Comunicação Social da Região Administrativa Especial de Macau publica um Livro do Ano que registra e divulga o desenvolvimento político-econômico e sociocultural do território. As informações presentes foram extraídas da versão do livro publicado em 2006.

${ }^{4}$ Os programas transmitidos pela Rádio Macau podem ser acessados no endereço eletrônico http://portugues.tdm.com.mo.
} 
Após traçar o perfil do entrevistado, o entrevistador emprega uma expressão iniciada por um cumprimento e seguida por uma pausa (...). Está lançada a pista de que o enquadre entrevista começou e que o entrevistado deve aproveitar a pausa para saudar o entrevistador e indicar que está engajado na atividade.

Logo a seguir, o entrevistador enuncia:

GL: patuá patrimônio intangível... vamos ter duas candidaturas... u::ma patrimônio intangivel da UNESCO e outra... patrimônio intangivel da RAEM... por quê?

Dessa forma, o entrevistador anuncia o tema selecionado para o momento da entrevista. Ao proferi-lo, ele informa que o enquadre saudação se encerrou e permite ao entrevistado inferir que o quadro operante nesse instante é o da discussão acerca do tema.

Mais adiante, o entrevistado declara:

MS: eu lembro muito bem quando fizemos a bênção da festa de São João em:: autêntico dilúvio

E: eu também ((risos)) a ideia é voltar este ano a fazer o São João...

Ao empregar a figura de linguagem ironia, o entrevistado declara ao entrevistador que a mensagem não deve ser interpretada literalmente, havendo um sentido subentendido - a de que essa festa de São João não foi uma bênção -, indício de que os participantes adentraram o enquadre piada.

$\mathrm{O}$ último momento que gostaríamos de destacar se dá quando o entrevistador pergunta se haverá um filme em patuá no próximo ano. $\mathrm{O}$ entrevistado responde:

MS: éb:: tenho as minhas dúvidas falando realisticamente... é claro também depende... depende das pessoas... mas o público este ano vai ver produções cinematográficas em pequena escala como:: fizemos no ano passado... o público vai ver isto ahn:: vai ver as producões:: as producões:: éb:: algumas produções cinematográficas em pequena escala... é tudo para testar a:: atenção do público... vamos ver éb:: SE as condiçöes se reunirem para fazer um filme e apresentar para o próximo ano... porque não? eu estaria muito:: éh:: ENtusiasmado para fazer isto... já o:: nosso:: cinematógrafo ((risos)) que eu chamo de capitão Sérgio... capitão Sérgio já:: anda a:: fustigar... a perguntar quando vamos falar sobre o:: filme... portanto ele é um dos elementos essenciais para este grande projeto que é... portanto:: vamos ver. 
Ao expressar o apelido do cinematógrafo do grupo Doci Papiaçam, o entrevistado apresenta a pista indicadora de que ele adentrou os domínios do enquadre brincadeira.

\section{Considerações finais}

A proposta de estudo elaborada permitiu constatar como cada sujeito se comporta na interação comunicativa ao mobilizar os recursos da linguagem para definir os enquadres situacionais e sinalizá-los.

Verificamos também que o andamento de um evento de fala exige que os participantes, caso estejam engajados na dinâmica comunicativa estabelecida, produzam e interpretem tais pistas para, então, se posicionar no jogo da linguagem.

\section{Referências}

FIORIN, J. L. A linguagem em uso. In: FIORIN, J. L. (org.). Introdução à Linguística I. São Paulo: Contexto, 2008, p. 165-186.

GOODY, J.; WATT, I. As Consequências do Letramento. Traduzido por Waldemar Ferreira Netto. São Paulo: Paulistana, 2006.

GUMPERZ, E. Convenções de Contextualização. Traduzido por José Luis Meurer e Viviane Heberle. In: RIBEIRO, B.; GARCEZ, P. (orgs.). Sociolinguística Interacional. São Paulo: Loyola, 2002, p.149-182.

HYMES, D. On communicative competence. In: PRIDE, J.B.; HOLMES, J. (Orgs.). Sociolinguistics. Hardmondsworth: Peguin Books, 1972, p. 241-281. MARCONDES, D. S. F. A Teoria dos Atos de Fala como concepção pragmática de linguagem. Filosofia Unisinos. São Leopoldo: Unisinos, 2006, v. 7, p. 217-230.

TANNEN, D.; WALLAT, C. Enquadres interativos e esquemas de conhecimento em interação. Traduzido por Parmênio Camurça Citó. In: RIBEIRO, B.; GARCEZ, P. (Orgs.). Sociolinguística Interacional. São Paulo: Loyola, 2002, p. 183-214. 